\title{
Google Glass in Face-to-face Lectures - Prototype and First Experiences
}

\author{
http://dx.doi.org/10.3991/ijim.v10i1.4834 \\ Markus Ebner, Herbert Mühlburger and Martin Ebner \\ Graz University of Technology, Graz, Austria
}

\begin{abstract}
Graz University of Technology has a long tradition in doing technology-enhanced courses. Following the latest trends, as mentioned in the NMC Horizon Report [32], we reviewed the possibility to use a wearable technology, in our case the Google Glass ${ }^{\mathrm{TM}}$, in courses to improve the interaction between the lecturer and the audience with a special focus on huge classes. The lack of interaction in traditional face-to-face lectures is a well-known problem with a long research history [4], [12]. New technologies in Audience Response Systems (ARS) offer new ways to improve the interaction between teacher and student by enabling to ask questions to the audience [5] to get instant feedback during a lecture. Currently many types of web-based ARSs are available on the market [15]. Our research focused on finding an ARS suitable for the visualization in the Google Glass display. Further we developed a prototype and described first practical experiences.
\end{abstract}

Index Terms-Audience Response System, face-to-face lecture, Technology Enhanced Learning, Wearable Technology

\section{INTRODUCTION}

The lack of interaction in traditional face-to-face lectures is a well-known problem with a long research history [4], [12]. The interaction between teachers and students is essential for learning according to educational theories [35], [31], [18]. "Educators and technologists alike are keenly interested in how wireless and mobile technology can enhance the way people learn and interact with each other. It is obvious that these m-learning technologies (elearning using mobile devices and wireless transmission) can potentially provide important opportunities for learning and collaborative interaction." [42]

This publication aims to discuss how Google Glass, a head-mounted display, impacts the interaction between a lecturer and the audience in face-to-face lectures as part of a so-called Audience Response System (ARS). Therefore we developed and tested a prototype to point out potentials and limitations of Google Glass in this context.

A lecture should assist active learning processes where lecturers interact with the audience but in mass lectures there are restrictions because of the big audience. Anderson [2] mentioned especially three big problems: the lack of feedback, the fear of students to ask and the singlespeaker paradigm.

Universities often use lecturing as preferred teaching method because it is an economical and efficient method of conveying information to large groups of students. One drawback of this method is the lack of interaction between lecturer and students [29]. On the other side it is difficult for the lecturer to assess the knowledge of the audience and the understanding of the presented learning materials.
For a lecturer information about speed and clarity of its language and the welfare of the audience is valuable too.

Systems like Audience Response Systems (ARSs) offer a proven way to interact with the audience during lectures. Such systems allow the lecturer to get instant feedback from an audience. Traditionally the audience used classic remote controls to answer questions anonymously using so-called "clickers". One possibility to motivate the audience to give feedback is to provide the opportunity to do so anonymously. Anonymity is important because people are more inclined to give feedback using anonymous voting systems [6]. In ARSs votes are collected, evaluated and visualized to the lecturer appropriately [5].

This paper discusses ARSs and the visualization of instant responses through Google Glass to the lecturer to enhance the interaction between students and lecturer. Therefore we try to answer the following research questions:

\section{A. Research questions}

RQ1: How can Google Glass be used as part of an ARS to enhance the interaction between lecturer and audience in face-to-face lectures?

RQ2: How can the lecturer get feedback during the whole lecture without being interrupted?

RQ3: How can Google Glass support the visualization of feedback and further improve the interaction between lecturer and audience in face-to-face lectures?

\section{B. Method}

To answer these research questions we developed a prototype [19] to visualize the feedback from the audience to the lecturer. According to Alavi [1] as well as Larson [24] prototyping is based on four steps: identifying basic requirements, development of a working prototype, implementation and usage (field study), and revision. In our particular case the prototype is based on data provided by ARS Backchannel, a web-based ARS developed at Graz University of Technology. We collected requirements, implemented a prototype for Google Glass and conducted a field study to test the usage in a real world lecture at Graz University of Technology in order to revise it according users' needs. In the field study a lecturer from Graz University of Technology uses the prototype in a real face-to-face lecture. We describe first experiences and additional findings during this usage.

\section{Contributions}

We describe technical aspects, potentials and challenges of Google Glass and ARS Backchannel in face-to-face lectures. We focus on three views and experiences: (a) view and experiences of the lecturer (b) view and experi- 
ences of the audience and (c) view and experiences of the developer of the prototype. Our results indicate that Google Glass is useful in face-to-face lectures but with certain constraints.

\section{Outline}

This paper is structured as follows: In section 2 we describe related work and section 3 points out the requirement as well as the implementation of our prototype. In section 4 we discuss our results emphasizing practical experiences and additional findings using the prototype in a real-world lecture. Section 5 discusses how an ARS can enhance lecturing and foster creativity in teaching. Section 6 concludes and describes future work.

\section{RELATED WORK}

Our research focuses on head-mounted wearable technologies for audience response systems. We try to integrate Google Glass as a head-mounted wearable technology in an existing ARS in order to increase the interaction between lecturer and audience. The following sections give background information on audience response systems such as ARS Backchannel and Google Glass as an example of a wearable technology.

\section{A. Audience response systems}

Audience response systems are also called personal response systems, electronic voting systems or student response systems [21]. They were developed by the military in the 1960s and mainly used for scenarios before their usage in classrooms of universities began [10], [20]. ARSs were complex and expensive to set-up and use due to they required a special infrastructure and a room with connected clickers to enable communication. Key and LeSage conducted a comprehensive literature review on Audience Response Systems and their benefits and challenges [21]: In 1996 Stanford University first introduced ARSs, which were expensive, difficult to use, and not working properly. In 1985 Christopher Newport University developed a less expensive ARS prototype called "Classtalk I", which gained widespread acceptance throughout the university. From 1992 to 1999 ARSs became commercially available but their high costs prohibited widespread distribution. In 1999 infrared ARSs became available and since 2003 numerous educational institutions made extensive use of ARSs [21].

Since the rise of wireless technologies ARSs have changed [7]. Before, in a lecture room every seat or every person had to be equipped with a remote control ("clicker"-system). Early versions of such clicker-systems consisted of just one answer button. Modern versions usually consisted of numeric keypads and further functions [5]. With wireless technology the system became portable, could be used in different lecture halls and was called Wireless Internet Learning Devices (WILD) [40]. For further literature on ARS we point to [36], [7], [44], [11], [3], [34], [15].

Finally the use of mobile devices with Internet connectivity such as smartphones and tablets has increased considerably in recent years [9]. Students bring these devices to the lecture and they can also be used as input devices for ARSs. The term "Bring Your Own Device" (BYOD) describes this policy [25], [26], [23]. Using own devices in ARSs bears the risk of distracting students from paying attention because they can be used in other ways than to give feedback. But a BYOD-policy offers beneficial ways for lecturers and the audience to interact in mass lectures [43].

\section{B. ARS Backchannel}

Backchannel is an easy, free and without registration usable backchannel-ARS which supports the BYODprinciple. It is a web application with state of the art technology such as HTML5, AngularJS ${ }^{1}$, responsive web design [28] and WebSockets.

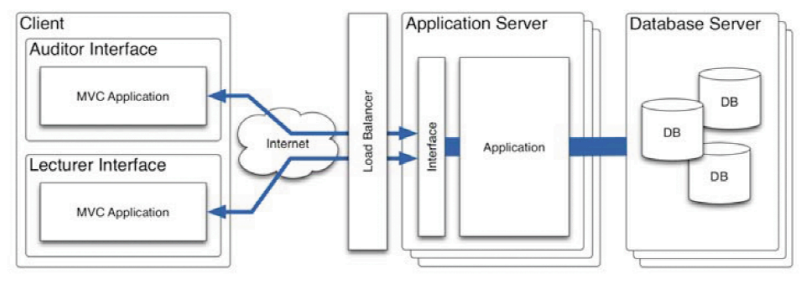

Figure 1. Architecture ARS Backchannel [14]

The architecture is based on a typical cloud-based web application architecture [14] as shown in Figure 1. The application server provides a pseudo RESTful server interface [39] and handles the whole communication from the audience and the lecturer. For dynamic horizontal scaling the application server and the database server (Redis ${ }^{2}$, MongoDB ${ }^{3}$ ) are running in the cloud. The application server is implemented with the pyramid framework ${ }^{4}$. The business logic on the client is implemented with the Model View Controller (MVC) [22] JavaScript framework AngularJS [14].

The near real time communication between the auditors and the lecturer is realized with WebSockets (Socket.IO ${ }^{5}$ Server version 0.9). To reduce complexity and possible performance bottlenecks, depending on the audience size and the number of simultaneous held lectures, the publishsubscribe pattern is used. This pattern sates that the sender of a message needs not to know the receiver. Receivers (the audience) are subscribing to channels and the publisher (the lecturer) does not care about the number of subscribers [14].

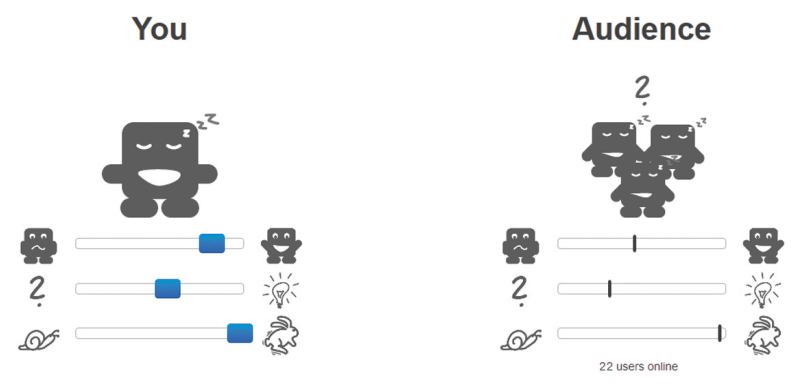

Figure 2. Audience view. On the left side the user can vote by adjusting the sliders for happiness, comprehension and speed. On the right side the perception of whole audience is shown

\footnotetext{
${ }^{1}$ AnguarJS: https://angularjs.org/ last visited on 2015, June 13

${ }^{2}$ Redis: http://redis.io/ last visited on 2015, June 13

${ }^{3}$ MongoDB: http://www.mongodb.org/ last visited on 2015, June 13

${ }^{4}$ Pyramid framework: http://www.pylonsproject.org/ last visited on 2015, June 13

${ }^{5}$ Socket.IO http://socket.io/ last visited on 2015, February 02
} 
On the website ${ }^{6}$ the lecturer can simply create a lecture for his audience. The audience can easily access the lecture by entering a 5-digit code provided by the lecturer. Afterward they can give feedback in three dimensions: happiness, comprehension and speed, as shown on the left side "You" in Figure 2. At the beginning the sliders are in the middle (neutral). Every auditor then can move the sliders to express their feelings to the left (negative) or to the right (positive). The right side "Audience" represents the feeling of the whole audience in the room. The simple structure of the interface e.g. the use of symbols instead of text makes it easy to understand and useable during the lecture. The image-based approach in the audience interface tries to utilize the Tamagotchi effect [17] for motivating the audience to keep participating during the lecture.

\section{Audience}

Join
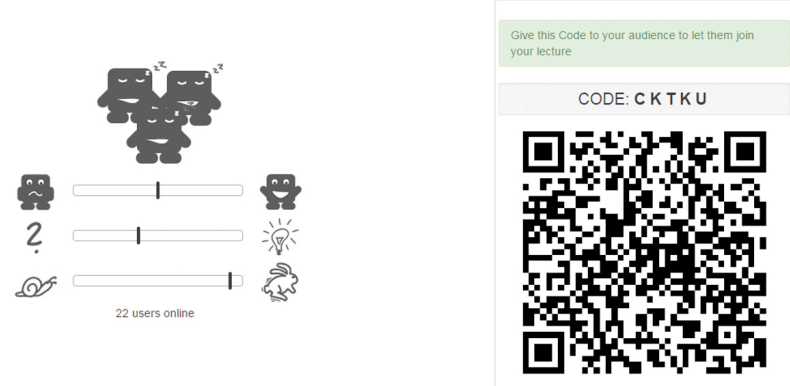

Figure 3. Lecturer view. On the left side the perception of the audience is shown. On the right side the 5-digit code and the QR-Code, used for the audience to join the lecture, are located.

In opposite, after creating a lecture the lecturer can see the feedback from the audience on the website as shown on the left "Audience" in Figure 3. On the right side the 5digit code for the audience is shown as well as a QRCode $^{7}$. The audience can either use the 5-digit code on the website or scan the QR-Code with a smartphone to join the lecture.

One important aspect of ARSs such as ARS Backchannel is the visualization of feedback from the audience to the lecturer in real-time. The visualization should be in sight of the lecturer but not distract lecturing [8]. One possibility to visualize the results is by using an additional screen in sight of the lecturer (e.g. an additional hardware (notebook or computer screen) other than the one used for the lecturer's presentation). But this is not an appropriate solution for lecturers that want to move around the room or need to use other media such as a blackboards or whiteboards. Getting feedback in the moment of every interaction is not possible because the lecturer would have to pay attention to the additional screen all the time. One solution to this problem could be the use of wearable technologies. Developers can use the provided Web application program interface (API) from ARS Backchannel to receive and process the feedback. In our case we decided to visualize the results on a smart glass.

\section{Wearable technologies}

"A wearable computer is a computer that is subsumed into the personal space of the user, controlled by the user,

\footnotetext{
${ }^{6}$ Backchannel: http://backchannel.cnc.io/ last visited on 2015, February 02

${ }^{7}$ QR-Code: "Stands for "Quick Response" code. It's a barcode - read by devices such as camera phones - that enables someone to display certain information or perform certain tasks such as opening a web page." [37]
}

and has both operational and interactional constancy, i.e. is always switched on and always accessible. Most notably, it is a device that is always with the user, and into which the user can always enter commands and execute a set of such entered commands, and in which the user can do so while walking around or doing other activities." [27].

Wearables differ from mobile devices such as smartphones or tablets in their appearance. These devices are worn on parts of a (human) body. Sometimes a conceptual link to the wearer's body is needed (e.g. a heartrate monitor wrist unit and chest belt). Depending on its intended user and task the user interface can allow input and output in many ways. These input devices can include a keypad, special keying devices, joysticks and touchpads along with other standard function-specific push buttons. LCD-displays and head mounted displays (HMD) are used as a graphic interface for output as well as sound and vibrations [30].

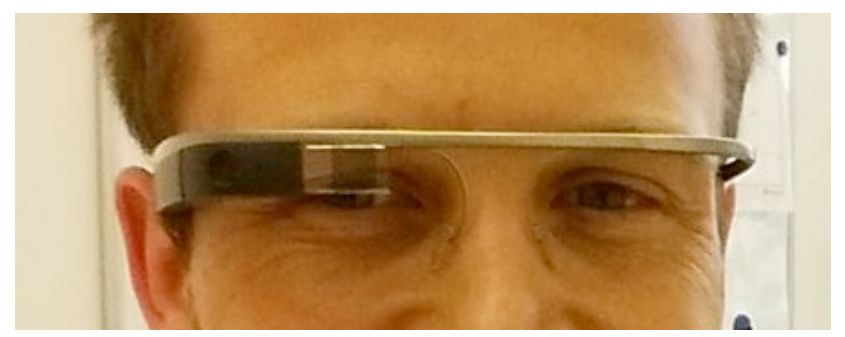

Figure 4. Google Glass in use

Google Glass is a head-mounted wearable technology. A head-up display (HUD) ${ }^{8}$ is used to present information in the user's line of sight, as shown in Figure 4. The display uses high-definition liquid crystal on silicon (LCOS) for projecting the image onto a prism, which then reflects an image onto the retina of the eye. The prism is located about an inch from the right eye. The user can see the equivalent of a 25-inch high-definition screen from around eight feet away [38].

The possible information presented on the display is limited through its size of $640 \times 360$ pixels. Services and applications for Google Glass are called Glassware. To install additional Glassware you can use the MyGlass ${ }^{9}$ app on your paired smartphone and browse the store for available applications. There is a video ${ }^{10}$ available online where the navigation and handling of a Google Glass is explained in detail.

Due to the cancellation of the Explorer program on Jan 15,2015 Google Glass has been pulled of the consumer market. Google excluded the Glass program from Google[x] and gave the project its own team to improve the product in design and handling for a future release [13]. For the business market it is still possible to attend in

\footnotetext{
${ }^{8}$ Head-up display: "An electronic display of instrument data projected at eye level so that a driver or pilot sees it without looking away from the road or course." [16]

${ }^{9}$ MyGlass app, available at Play Store: https://play.google.com/store/apps/details?id=com.google.glass.compan ion or Apple iTunes: https://itunes.apple.com/us/app/myglass/id761310950 last visited on 2015, February 02

${ }^{10}$ Google Glass How-to: Getting Started, available online: http://youtu.be/4EvNxWhskf8 last visited on 2015, February 02
} 
the Glass at Work ${ }^{11}$ program for buying a Google Glass and developing business solution for it.

\section{PRototype}

This section describes collecting the requirements on an ARS that uses Google Glass to visualize feedback and the implementation of the prototype. Further we describe the development environment and the view imposed by the display of Google Glass as we are interested in visualizing feedback results.

\section{A. Requirements}

There are many different ARSs on the market and based on our academic literature review in section 2 and an internet research [41] on existing ARSs we defined the following main requirements for the usage of Google Glass in an ARS for a prototype:

- Using the device by a lecturer should be possible during an entire lecture.

- Provided information on the display should be informative, easy to understand and not disruptive.

- Provided information to the lecturer must fit the Google Glass display size of 640x360 pixels and blend in the visual field appropriately.

- The system must be simple and easy to use so that the audience is encouraged to provide feedback through the ARS.

- The principle of BYOD should be supported.

Based on these requirements and the restrictions of the display of Google Glass we decided to use the ARS Backchannel [14] as ARS for our prototypical implementation. Most of the ARSs reviewed in section 2 are "frontchannel-systems". To interact in a lecture questions are asked directly to the audience and the lecture gets interrupted. They consist of quantitative and qualitative answers. Typically single or multiple-choice answers are available in quantitative systems in opposite to qualitative systems where answers are provided as free text input [15]. The other type of ARS is a "backchannel-system" which offers the same functionality, but the lecture is not interrupted. Probably the best known backchannel-system is Twitter [7]. It runs in the background during a lecture and can be used by the audience when needed, e.g. asking questions to the lecturer or giving continuous feedback about the speed or comprehension of the course in real-time [8].

With frontchannel-systems the Google Glass cannot be used appropriately. The lecture is interrupted and questions are asked and answered. There is no practical benefit in using a Google Glass to consume answers by the audience. Also qualitative systems are difficult to use with Google Glass. It showed that texts sent from the audience during the lecture are more a distraction than a benefit for the lecturer. The small size of the Google Glass display makes them very hard to read.

Considering the defined requirements and restrictions of the display of Google Glass we decided to use a quantitative backchannel-system, the ARS Backchannel [14], for continuous real-time feedback during the lecture.

\footnotetext{
${ }^{11}$ Glass at Work program, available online:

https://developers.google.com/glass/distribute/glass-at-work last visited on 2015 , June 13
}

\section{B. Implementation}

Backchannel provides a QR-Code in the Lecturer view as shown in Figure 3. We used the Barcode Scanner from the zebra crossing ${ }^{12}$ (ZXing) project to extract the 5-digit code which is needed for the Web API to join the lecture. The subscription to the appropriate channel on the server is realized with the socket.io-java-client ${ }^{13}$. After subscription the client will receive the new stats whenever another user has voted and changed the stats of the three feedback dimensions. Both libraries are open-source and can be used to establish the connection to the Backchannel server on different wearable devices.

The prototype for the Google Glass has been developed with the Eclipse Android Development Tools (ADT) and the Glass Development Kit (GDK). At this point of time (June 2014) it was the recommend tool to use. Software and detailed documentation can be found online ${ }^{14}$. Google Glass is using a modified Android 4.4.2 as operating system. In Eclipse it is necessary to install the Android 4.4.2 Software Development Kit (SDK), the Glass Development Kit Preview and the Google USB Driver. For testing the Glassware Google Glass needs to be connected with the Computer because there is no official Emulator for Glassware available yet.

Google Glass uses the lecturer view of the ARS Backchannel to present the three feedback dimensions to the lecturer, as shown in the chapter related work.

Prototype display view: The prototype mirrors the lecturer view from the website to serve the lecturer as an additional consumption possibility of the feedback provided by the audience.

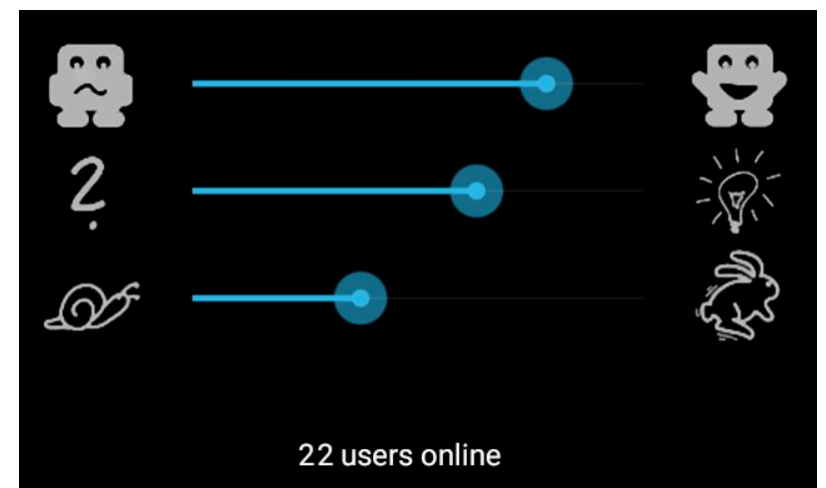

Figure 5. Feedback view for the lecturer throw the prism

The feedback on the Google Glass Display is presented to the lecturer as shown in Figure 5. The three dimensions happiness, comprehension and speed are visualized with a blue line and a dot. The length of the bar indicates the general feeling of the audience. The longer the line, the better. On the bottom the number of currently participating persons from the audience is shown.

\section{Results}

This section describes our practical experiences using Google Glass for interacting in face-to-face lectures at

\footnotetext{
${ }^{12}$ ZXing project home https://github.com/zxing/zxing last visited on 2015, June 13

${ }^{13}$ Socket.io-java-client: https://github.com/fatshotty/socket.io-javaclient/tree/socket.io-client-0.2.1 last visited on 2015, June 13

${ }^{14}$ Eclipse ADT: http://developer.android.com/tools/sdk/eclipse-adt.html last visited on 2015, February 02
} 
PAPER

Graz University of Technology. We concentrated on technical aspects as well as possible potentials and limitations of Google Glass and ARS Backchannel carried out by a first field study.

We tested the implementation of the prototype in a realworld lecture at Graz University of Technology. The lecturer used the developed Glassware while lecturing. The first test was performed in a typical seminar. In future tests are planned to evaluate the developed prototype in a bigger setting. But although the field study was in a smaller setting some interesting results were found. In the field study we concentrated on three aspects of different people: (a) view and experiences of the lecturer (b) view and experiences of the audience and (c) view and experiences of the developer of the prototype. We were interested in observing how the audience reacts on Google Glass and how the lecturer uses feedback through Google Glass during the lecture. Furthermore we were also interested in technical problems which we describe in the last part of this section.

\section{A. Set-up and witnessed responses}

The lecturer and the audience were first introduced to Google Glass and ARS Backchannel. Then the lecturing was performed and after the lecture we discussed the experiences with the lecturer and with volunteers from the audience. These experiences and the setting of the field study are discussed in more detail in the following sections.



Figure 6. The lecturer in front of the audience with Google Glass

During the field experiment the lecturer walked freely in the room holding a presenter-stick in his hand to continue with the slides, see Figure 6. Google Glass was mounted on the head of the lecturer and visualized the response from ARS Backchannel in his line of sight. What we observed was that the lecturer changed his style of lecturing in accordance to the feedback from the audience provided only through the display of Google Glass several times. We witnessed a slowdown of language speed caused by the feedback of the audience through the ARS. The lecturer also gave more explanations on several topics in response to the ARS feedback of the audience. The reaction of the lecturer and the audience was general positive. The possibility to give feedback with the ARS Backchannel and to visualize this feedback using Google Glass was a benefit. In the next sections we describe the different views and experiences from the participants of the field study and the development of the Google Glass prototype.

\section{B. Experiences of the lecturer}

One of the first things that the lecturer encountered was a connection problem regarding the Internet connection. Google Glass could not connect to the wireless university network because WPA2 Enterprise is not supported. One solution was to pair Google Glass with a smartphone, which was connected to the wireless university network. After fixing this issue the lecture started. The handling of the Google Glass prototype itself was intuitive and selfexplaining. The steps to start the Google Glass prototype called "Backchannel" were easy to perform. After starting the prototype Google Glass was ready for use: At the beginning the lecturer needed some minutes to get used to the provided visualization at the top right of his line of sight. After this disturbing phase the lecturer got used to the visualization and did not feel disturbed any more. The visualization contained three dimensions regarding happiness, comprehension and speed. The provided feedback through these visualizations was taken into account several times by the lecturer leading to an increased reaction to the feedback of the audience.

From a lecturer point of view the use of Google Glass in large classes does indeed lead to a new kind of interaction with the audience. It enables to get more feedback than you would get otherwise. Shy persons are more likely to give feedback in our scenario. It also enables lecturers to engage the audience when necessary through reacting on the given feedback. E.g. to slow down in lecturing speed or to explain certain details in another way or just to create a common view of certain points by making the feedback transparent and accessible to everybody during the lecture.

\section{Experiences of the audience}

At the end of the lecture volunteers from the audience were chosen randomly to point out their experiences and feelings during the lecture. Some of the volunteers were also lecturers by their own and we were interested to know if they would use Google Glass and an ARS in future. Additionally we asked the volunteers the following questions via qualitative interviews. Finally their experiences had been collected and summed up to point out crucial facts:

How did you feel during the presentation? This question was answered by four people with "as always". Only two people felt observed by Google Glass and expressed their concerns about this technology.

Could you imagine using Google Glass during a lecture? Four of them would use it during a lecture. For others the lecturer looked distracted during the lecture and found Google Glass unsuitable for use during a lecture.

Additional comments on Google Glass? One person was concerned about the privacy of Google Glass, especially about the camera and the microphone and that there is now way to see if it is in use or not.

Would you use the system Backchannel (without Google Glass)? Here everybody agreed that the use of ARS Backchannel offers advantages and is a good way to encourage students for feedback and improve interactions during lectures.

Do you think it makes sense to give feedback with ARS Backchannel? Four people answered here with "Yes". Two would use it partially, but not consistently. They 
have concerns about the potential distraction in a longterm use.

\section{Experiences of the developer}

During the development phase and the field study the following points have been faced specific with the Google Glass. The information provided in this paragraph may help future developers to consider these experiences in their choice of product when creating use case scenarios for smart glasses.

Eyeglasses and debility of sight: If the lecturer already wears eyeglasses Google Glass could either be placed above them or not depending on the design of the eyeglass frame. The presented information in the prism of Google Glass is not shown properly, as it is designed for people without visual impairment. To get the best-augmented vision with Google Glass, if you have amblyopia, it is recommended to use either the spectacle frame that comes with the package and fit in optical glasses, or wear daily lenses while using the Google Glass.

Light sources in the environment: During testing we found out that the image in the prism is only clearly visible in darker environments. Depending on the surrounding light sources, as well as the background the user is looking at, the information in the Google Glass prism is either good or difficult to see. Bright environments or backlight make it almost unrecognizable. To achieve the best possible view results we preferred to use a dark background with white text. To ensure best readability we preferred to use short text in large font where possible.

Display size and information presentation: The display has a size of 640x360 pixels. There is not much space for text. We found out that more than 70 characters are very hard to read because the size changes dynamically with the amount of text. For a good user experience it is essential to keep the provided information short, simple and relevant to the current task.

No keyboard: Google Glass can be controlled with touch gestures and voice commands. Without using additional Glassware and a Bluetooth keyboard, the only easy way to get additional information is via QR-Code. In the prototype we used a QR-Code for the Glassware "Backchannel" to fetch the lecture ID from the ARS Backchannel website. It is possible that in the future Google will present new ways to interact with Google Glass, e.g. with a laser-projected keyboard [33].

Habituation effect: The interaction of Google Glass is different from the one with smartphones. Which means that the lecturer needs to get used to the equipment before its usage in a real lecture. It is necessary that the lecturer becomes familiar with different states and the visualization of feedback results using the device.

Heat generation: Google Glass heats up with continuous use. Computationally intensive Glassware causes a fast heating of the hardware. The user can feel that in the right temple, which may cause distraction or an unpleasant feeling. During the prototype testing a temperature around 30 degrees Celsius has been measured. Maybe future improvements on the hardware will resolve the heating problem with Google Glass.

Restricted run-time: The average run-time for the active glassware "Backchannel" on the prototype is approximately 1.5 to 2 hours and should be sufficient for most lectures. If the lecture lasts longer a battery pack can be used to extend the run-time. However, the micro-USB cable, which is used to power Google Glass, may cause discomfort to the speaker.

Internet connection: Google Glass can only connect to password protected wireless networks. These networks can be added by QR Code or with the aid of the MyGlass application on the paired smartphone. If the network needs further authentication with username and password, for example in WPA-Enterprise networks, it is not possible to connect to the network without pairing Google Glass with a smartphone.

\section{DISCUSSION - HOW CAN ARS ENHANCE LECTURING AND FOSTER CREATIVITY IN TEACHING}

Google Glass in combination with an ARS system can enhance teaching in manifold ways. So different teaching and therefore also learning scenarios are imaginable. For example we would like to outline the following possibilities, but of course the usage is not restricted to only those ones:

Instant Feedback: Obviously it can be used for just-intime feedback for teachers from the (large) audience. This is even possible during very traditional settings where teacher write on the blackboard and cannot take any look to another display.

Qualitative and quantitative backchannel: The feedbacks for teachers are also interesting in combination with a qualitative backchannel, where learners can be asked for a certain answer through multiple choice questions. So if something is not understandable, additional questions can help to address the exact problem.

Feedback from outside: If the audience is a mixed (lecture hall and online) one, such a possibility helps to get also in touch with the live streaming watching, virtual audience.

Simple voting: The system will also assist so called yes/no question in a large lecture hall. For example one dimension can be used for a yes/no voting. Teachers will see very quickly how many of the audience are voting for yes or no.

Anonymously voting scenario: A further didactical approach is to use the system for anonymously feedback from peers. If students have to judge e.g. about presentations of their colleagues, this will be visualized easily.

Assisting moderation process: The system can also be used for enhancing a discussion. The audience can give the moderator instant feedback about how the discussion is going on, who will be able to react appropriate.

\section{CONCLUSIONS}

Wearable technologies offer a new way of presenting information to the lecturer. We have presented a possible use case for Google Glass to assist lecturers during lectures. First we evaluated the possibilities and decided to use an ARS with BYOD-principle for improving the interaction between the lecturer and the audience. A prototype was developed and used during a field experiment. We observed the reactions from the lecturer and the audience and discussed their experiences as well as the experiences of the developer of the prototype. The first field study pointed out that Google Glass has benefits in faceto-face lectures and increases the interaction with the audience. But users should be aware of certain constraints 
imposed by the limited size of the display and the different way of interaction with the device.

The research study presented how Google Glass can be used in combination with an ARS system through an API and an app based on an Android operation system. (RQ1). Furthermore the first field study pointed out that the lecturer get instant feedback of the audience without any interruption. He mentioned that after some time the visualization was not distracting him from lecturing, but he recognized definitely if one of the dimensions changed arbitrarily (RQ2). In the end the research study aimed to improve the existing ARS system through a better visualization technique. Due to the fact that without Google Glass at least two displays were (one for the lecture content and one for the ARS results) necessary, the teacher was very satisfied with this kind of solution (RQ3). He even stated that "it's great to have the chance to get feedback during walking through the lecture hall or writing on the blackboard".

New technologies always bring new problems to which the society is not prepared. Privacy is a concern, which needs to be considered when using Google Glass. The possibility to use the camera without noticing it in the audience was a concern of the audience. People in the audience felt observed, which can deflect them during the lecture. Further investigation in this context would be necessary.

We plan to test the further developed prototype in massive face-to-face lectures with more participants to collect more aspects of using Google Glass in an ARS. Smart watches could be a possible extension to our setting and we plan to integrate them too in our future work.

\section{REFERENCES}

[1] M. Alavi, "An assessment of the prototyping approach to information systems development," in Commun. ACM 27. 6, June 1984, pp. 556-563.

[2] R. J. Anderson, et al., ,Promoting interaction in large classes with computer-mediated feedback," in Designing for change in networked learning environments. Proceedings of CSCL 2003., 2003, pp. 119-123.

[3] C. Atkinson, "The Backchannel: How Audiences are Using Twitter and Social Media and Changing Presentations Forever," New Riders, 2009.

[4] D. A. Bligh, "What's the Use of Lectures," Devon, England: Teaching Service Centre, University of Exeter, 1971.

[5] J. E. Caldwell, "Clickers in the Large Classroom: Current Research and Best-Practice Tips," CBE-Life Sciences Education, vol. 6 no. 1 , pp. 9-20, 2007. http://dx.doi.org/10.1187/cbe.06-120205

[6] Q. I. Cutts and G. E. Kennedy, "Connecting Learning Environments Using Electronic Voting Systems," in Proceedings of the 7th Australasian Conference on Computing Education Volume 42, 2005, pp. 181-186.

[7] M. Ebner, "Introduction live microblogging: how single presentations can be enhanced by the mass," Journal of research in innovative teaching, pp. 91-101, 2009.

[8] M. Ebner et al., "Technologiegestützte Echtzeit-Interaktion in Massenvorlesungen im Hörsaal. Entwicklung und Erprobung eines digitalen Backchannels während der Vorlesung," in Lernräume gestalten-Bildungskontexte vielfältig denken, 2014, pp. 567-578.

[9] M. Ebner et al., "Have They Changed? Five Years of Survey on Academic Net-Generation," in World Conference on Educational Media and Technology, 8, 2012, pp. 21-31.

[10] H. P. Froehlich, "What about Classroom Communicators?" in Audio Visual Communication Review 11.3, 1963, pp. 19-26.

[11] V. Gehlen-Baum et al., "Technology Use in Lectures to Enhance Students' Attention," in Open Learning and Teaching in
Educational Communities, Springer International Publishing, 2014, pp. 125-137.

[12] M. Gleason, "Better communication in large courses," College Teaching, 34 (1), 1986, pp. 20-24. http://dx.doi.org/10.1080/8756 7555.1986 .10532325

[13] Google+. (2015, June 13). We're graduating from Google [x] labs. Available:

https://plus.google.com/+GoogleGlass/posts/9uiwXY42tvc

[14] C. Haintz, "Quantitative Digital Backchannel: Developing a WebBased Audience Response System for Measuring Audience Perception in Large Lectures," M.S. thesis, Graz University of Technology, Graz, Austria, 2013.

[15] C. Haintz et al., "Developing a Web-Based Question-Driven Audience Response System Supporting BYOD," in Journal of Universal Compuer Science, 20 (1), 2014, pp. 39-56.

[16] Dictionary.com Unabridged. (2015, March 04). heads-up display. Available: http://dictionary.reference.com/browse/heads-up display

[17] A. Holzinger et al., "TRIANGLE: A Multi-Media test-bed for examining incidental learning, motivation and the TamagotchiEffect within a Game-Show like Computer Based Learning Module," in C. Montgomerie \& J. Viteli (Eds.), Proceedings of World Conference on Educational Media and Technology 2001, Association for the Advancement of Computing in Education (AACE), 2001, pp. 766-771.

[18] A. Holzinger, Multimedia Basics, Volume 2: Learning. Cognitive Fundamentals of multimedial Information Systems, New Delhi: Laxmi, 2002.

[19] A. Holzinger et al., "From extreme programming and usability engineering to extreme usability in software engineering education $(\mathrm{XP}+\mathrm{UE} \rightarrow \mathrm{XU})$, , in Computer Software and Applications Conference 2005. COMPSAC 2005. 29th Annual International. Vol. 1, 2005, pp. 169-172.

[20] E. Judson and D. Sawada, "Learning from Past and Present: Electronic Response Systems in College Lecture Halls," in Journal of Computers in Mathematics and Science Teaching 21.2, 2002, pp. 167-181.

[21] R. H. Kay and A. LeSage, "Examining the benefits and challenges of using audience response systems: A review of the literature," in Computer \& Eductaion(53), 2009, pp. 819-827.

[22] B. Taraghi and M. Ebner, "A simple MVC framework for widget development," In Proceedings of the International Workshop on Mashup Personal Learning Environments (MUPPLE). CEUR-WS, 2010, pp. 38-45.

[23] S. L. Lam et al., "Classroom communication on mobile phones first experiences with web-based 'clicker' system," in Ascilite Conference 2011, 2011, pp. 763-777.

[24] O. Larson, "Information Systems prototyping," in Proceedings Interest HP 3000 Conference., Madrid, 1986, pp. 51-364.

[25] R. Lennon, "Bring Your Own Device ( BYOD ) with Cloud 4 Education," in SPLASH '12, 2012, pp. 171-179.

[26] Logicalis, "BYOD: an emerging market trend in more ways than one," Technical report., 2012, pp. 1-12.

[27] S. Mann, "Wearable computing as means for personal empowerment," in Proc. 3rd Int. Conf. on Wearable Computing (ICWC), 1998.

[28] E. Marcotte, Responsive web design, A Book Apart, 2011.

[29] U. Matti, M. Renko and H. Soini, "Experiences of using an interactive audience response system in lectures," in BMC Medical Education, 3(1), 12, 2003. http://dx.doi.org/10.1186/1472-6920-312

[30] J. McCann and D. Bryson, Smart clothes and wearable technology. Elsevier, 2009. http://dx.doi.org/10.1533/97818 $\underline{45695668}$

[31] R. Motschnig-Pitrik and A. Holzinger, "Student-Centered Teaching Meets New Media: Concept and Case Study," in IEEE Journal of Education Technology \& Society. 5(4)., 2002, pp. 160172.

[32] New Media Consortium. (2015, January 28). The NMC Horizon Report 2014: Higher Education Edition. Available: http://cdn.nmc.org/media/2014-nmc-horizon-report-he-EN-SC.pdf 
PAPER

GOOGLE GLASS IN FACE-TO-FACE LECTURES - PROTOTYPE AND FIRST EXPERIENCES

[33] Phys.org. (2015, December 12). Google Glass may run with laserprojected keyboard. Available: http://phys.org/news/2013-01google-glass-laser-projected-keyboard.html

[34] K. Pichler, "Relevant Information and Information Visualizations for Lecturers in Web-Based Audience Response Systems," M.S. thesis, Graz University of Technology, Graz, Austria, 2013.

[35] J. Preece et al., "Interaction Design: Beyond Human-Computer Interaction," New York: Wiley, 2002.

[36] P. Purgathofer and W. Reinthaler, "Massive "Multiplayer" ELearning," in World Conference on Educational Media and Technology, Vienna: Association for the Advancement of Computing in Education (AACE), 2008, pp. 2015-2023.

[37] Stanford University IT. (2015, February 02). QR-Code. Available:

https://itservices.stanford.edu/service/web/mobile/about/terminolo gy

[38] E. Redmond, Programming Google Glass (1 ed.). Pragmatic Bookshelf, 2013.

[39] L. Richardson and S. Ruby. RESTful Web Services. O'Reilly Media, Inc., 2008, p. 454.

[40] J. Roschelle, "Unlocking the learning value of wireless mobile devices," in Journal of Computer Assisted Learning 19, 2003, pp. 260-272. http://dx.doi.org/10.1046/j.0266-4909.2003.00028.x

[41] shambles.net. (2015, February 02). Shambles Backchannel List. Available: http://www.shambles.net/pages/staff/BCtools/

[42] M. Sung, et al., "Mobile-IT Education (MIT. EDU): m-learning applications for classroom settings," in Journal of Computer Assisted Learning 21.3, 2005, pp. 229-237.
[43] G. Thomson, "FEATURE BYOD : enabling the chaos," in Network Security, 2012(2), 2012, pp. 5-8.

[44] S. Yardi, "The role of the backchannel in collaborative learning environments," in ICLS '06 Proceedings of the 7th international conference on Learning sciences, 2006, pp. 852-858.

\section{AUTHORS}

Markus Ebner is with the Institute of Information Systems and Computer Media at Graz University of Technology, Graz, Austria (e-mail: markus.ebner@tugraz.at).

Herbert Mühlburger was with the Institute of Business Economics and Industrial Sociology at Graz University of Technology, Graz, Austria. He is now a Full-StackDeveloper at Scoop \& Spoon, Graz, Austria (e-mail: herbert.muehlburger@gmail.com)

Martin Ebner is with the Social Learning Department at Graz University of Technology, Graz, Austria. (e-mail: martin.ebner@tugraz.at). As head of the Department he is responsible for all university wide e-learning activities. He holds an Assoc. Prof. on media informatics and works also at the Institute for Information System Computer Media as senior researcher. For publications as well as further research activities, please visit: http://martinebner.at

Submitted, 01 July 2015. Published as resubmitted by the authors on 06 August 2015. 